\title{
Adsorption of diazinon from aqueous solutions onto an activated carbon sample produced in Iran
}

\author{
Zeynab Akbarlou', Vali Alipour ${ }^{2 *}$, Mohsen Heidari², Kavoos Dindarloo ${ }^{3}$ \\ ${ }^{1} \mathrm{MSc}$ of Environmental Health Engineering, Student Research Committee, Department of Environmental Health Engineering School \\ of Health, Hormozgan University of Medical Sciences, Bandar Abbas, Iran \\ ${ }^{2}$ Assistant Professor of Environmental Health Engineering, Department of Environmental Health Engineering, School of Health, \\ Hormozgan University of Medical Sciences, Bandar Abbas, Iran \\ ${ }^{3}$ Associate Professor of Environmental Health Engineering, Department of Environmental Health Engineering, School of Health, \\ Hormozgan University of Medical Sciences, Bandar Abbas, Iran
}

\begin{abstract}
Background: Considering the severe health and environmental hazards caused by the entry of diazinon toxin into water resources, its removal is very important. Given the high costs of imported adsorbents, this research attempted to evaluate, for the first time, the efficiency of Iranian activated carbon in removing diazinon from aqueous solutions.

Methods: In this batch experimental study, the effects of contact time (5-90 minutes), adsorbent concentration (0.5-30 g/L), initial concentration of diazinon $(5-50 \mathrm{mg} / \mathrm{L})$, and $\mathrm{pH}(3-10)$ on the adsorption of diazinon onto the activated carbon were evaluated. Concentrations of diazinon were measured using a high pressure liquid chromatography (HPLC) instrument. The specific surface area of the adsorbent was determined by BET and BJH methods. The experimental adsorption data was analyzed using Langmuir and Freundlich isotherm models. Pseudo first-order and pseudo second-order kinetics models were employed to determine kinetics. Moreover, data was analyzed using SPSS version 19, and Pearson correlation and analysis of variance (ANOVA) tests were performed at a significance level of 0.05 .

Results: The optimum contact time, sorbent dose, and $\mathrm{pH}$ were 30 minutes, $10 \mathrm{~g} / \mathrm{L}$, and 5, respectively. The adsorbent could adsorb diazinon with a removal efficiency of $92.5 \%$ under optimum conditions (initial concentration: $20 \mathrm{mg} / \mathrm{L}$ ). The experimental data was better described by the pseudo-second order kinetic and Langmuir isotherm. A maximum adsorption capacity of $71.4 \mathrm{mg} / \mathrm{g}$ was calculated by the Langmuir isotherm model.

Conclusion: With respect to the high adsorption capacity of Iranian activated carbon, this sorbent can be considered an efficient adsorbent for the removal of diazinon from aqueous solutions.

Keywords: Diazinon, Adsorption, Activated carbon, High pressure liquid chromatography

Citation: Akbarlou Z, Alipour V, Heidari M, Dindarloo K. Adsorption of diazinon from aqueous solutions onto an activated carbon sample produced in Iran. Environmental Health Engineering and Management Journal 2017; 4(2): 93-99. doi: 10.15171/EHEM.2017.13.
\end{abstract}

\section{Article History:}

Received: 13 December 2016

Accepted: 18 January 2017

ePublished: 20 February 2017

\section{Introduction}

Insecticides and pesticides are among the most serious toxins found in various water resources (1). The widespread use of pesticides to control pests and develop agriculture has resulted in the pollution of surface water and groundwater, because these pesticides enter water resources through various routes including wastewater disposal, direct washing of pesticides, surface runoff, agricultural drainage water, erosion, aerial application, and others. This pollution has become a serious environmental problem in recent years (2-4). The entrance of these pollutants into water resources, especially sources of drinking water, can have adverse effects on human and environmental health, because they are highly resistant to environmental factors, very soluble in water, and toxic to living organisms
$(5,6)$. The extent of water pollution by toxins depends on the distance between the water resource and the sprayed area, the amount of precipitation, soil permeability, soil type, and other factors (7).

The degree to which people are adversely affected by the toxins depends on the quality of the chemicals, the length of time they are used, the duration of human exposure to them, the concentration of the pesticide, and the degree of its toxicity $(8,9)$. Results of some research have shown that pesticide application causes human health complications, including abortion, mental retardation, defective fetuses, and potential carcinogenesis and mutation (10,11). Moreover, the results of some studies suggest that environmental factors, especially the use of pesticides, are reasons for the increased prevalence of diabetes $(12,13)$. 
To date, international organizations have classified more than 56 pesticides as carcinogenic agents for laboratory animals. According to reports from these organizations, the use of some pesticides has been banned and the use of others has been limited in some countries (10).

Since the use of organochlorine insecticides has been banned, organophosphate pesticides are increasingly being used all over the world to control pests $(1,8,9)$. However, organophosphate pesticides are relatively volatile and enter the human body through contract with the skin and through the respiratory system (13). They suppress cholinesterase, overstimulate neurons, and cause neurological side effects $(9,11,13,14)$.

Diazinon is one organo-phosphorus insecticide used to control a broad spectrum of pests in agriculture and at home (15). The World Health Organization (WHO) has classified it as a class II pesticide. Its toxicity for aquatic organisms is $350 \mathrm{ng} / \mathrm{L}$, and its lethal dose for humans is about $90-444 \mathrm{mg} / \mathrm{kg}$ body weight (15-18). According to German standards, its maximum acceptable residue level is $1 \mathrm{ppm}$ (15).

The need to remove contaminant pesticides from water resources and the high costs that will result in case of failure to take proper action about this has instigated the use of various methods and advanced oxidation processes including Fenton-like, Fenton, photo Fenton, $\mathrm{UV} / \mathrm{H}_{2} \mathrm{O}_{2}$, $\mathrm{UV} / \mathrm{TiO}_{2}, \mathrm{UV} / \mathrm{O}_{3}$, iron nanoparticles, usual oxidation, coagulation and flocculation, precipitation, membrane filtration, microfiltration and reverse osmosis, nanofiltration, biological degradation, and adsorption processes. Advanced oxidation and membrane methods are not affordable, require large amounts of coagulants thus producing large amounts of sludge, and has low efficiency in the removal of bio-degradable matter. Adsorption methods are most commonly employed because of their low costs and easy operation (4,19-27).

One method for the removal of pesticides is the use of adsorbents, the most important of which is activated carbon (27-30). Because of its high porosity, activated carbon provides a large surface for the adsorbable material. The adsorption process is either physical or chemical. Covalent bonds and van der Waals forces are involved in physical and chemical adsorption, respectively (31).

Considering that diazinon is used extensively in Iran for various health-related and agricultural purposes, and given its persistence in the environment, worries remain concerning the adverse effects of this pollutant on human health and the environment. Moreover, the high cost of importing activated carbon has prevented its removal from vast areas that have been exposed to this pesticide. Therefore, in line with the policies of resistive economy and national self-sufficiency, the use of domestically produced products has received top priority. This research purposed to study the efficiency of domestically produced activated carbon in removing diazinon from aqueous solutions as a function of contact time, adsorbent dosage, $\mathrm{pH}$, and initial concentrations of diazinon parameters.

\section{Materials and methods}

This batch study was carried out on a laboratory scale. Diazinon with 99\% purity was purchased from the German Company Sigma Aldrich, and activated carbon produced in Iran was obtained from domestic companies. Stock diazinon solution at a concentration of $1000 \mathrm{mg} / \mathrm{L}$ was prepared by dissolving $0.1 \mathrm{~g}$ of diazinon in $100 \mathrm{~mL}$ of pure methanol (high pressure liquid chromatography - HPLC grade). All experiments were carried out in batch reactor (Erlenmeyer flasks). Contact time $(5,15,30,45$, 60 , and 90 minutes), dose of activated carbon $(0.5,1,3$, $5,10,20$, and $30 \mathrm{~g} / \mathrm{L})$, initial diazinon concentration (5, $10,20,30$, and $50 \mathrm{mg} / \mathrm{L})$, and $\mathrm{pH}(3,5,7,9$, and 10$)$ were the studied variables. The optimum value for each variable was determined by altering it while maintaining other variables constant. After adding activated carbon to the samples on a shaker at the speed of $200 \mathrm{rpm}$, their volumes were raised to $100 \mathrm{~mL}$. The samples were centrifuged at $3000 \mathrm{rpm}$ for 10 minutes, passed through a $0.45 \mu \mathrm{m}$ pore size syringe filter, and injected into an HPLC instrument (model Shimadzu) to determine their concentrations. The chromatography conditions for diazinon analysis were isocratic reversed-phase in a C-18 column with a water/ methane mobile phase using a 70/30 mixture, UV detector at wavelength of $220 \mathrm{~nm}$, and flow rate of $1 \mathrm{~mL} / \mathrm{min}$ (15). Specific surface area, pore volume, and average pore diameter were determined using BET and BJH methods. SPSS version 19 was used to calculate Pearson correlation coefficient and analysis of variance (ANOVA) at a significance level of 0.05 to analyze the data, and Excel 2013 was used to draw the diagrams.

\section{Results}

Characteristics activated carbon

Results of BET and BJH experiments performed to determine the characteristics of the activated carbon produced in Iran are presented in Table 1.

Based on the two afore-mentioned methods, the mean of the studied PAC specific area was $136.5 \mathrm{~m}^{2} / \mathrm{g}$; the $\mathrm{BJH}$ method was used to measure the micro pores (the main pores in adsorption), and a high portion of micropores specific area to total specific area (69\%) was noted. It was also noted that the studied PAC had a good quality in this area.

\section{Effects of contact time}

Figure 1 shows the effects of contact time on the removal of diazinon by activated carbon produced in Iran at the

Table 1. Characteristics of the studied activated carbon

\begin{tabular}{lllll}
\hline Specific area (BET method) & Specific surface area (BJH method) & Total pore volume & Average pore size \\
\hline $161.53 \mathrm{~m}^{2} / \mathrm{g}$ & $111.53 \mathrm{~m}^{2} / \mathrm{g}$ & $0.2-16 \mathrm{~cm}^{3} / \mathrm{g}$ & $4.9919 \mathrm{~nm}$ & \\
\hline
\end{tabular}


constant concentration of $20 \mathrm{mg} / \mathrm{L}$ and neutral $\mathrm{pH}$. As shown in the diagram, the percentage of diazinon removed improved with increases in contact time up to 30 minutes; the maximum removal rate of $48.7 \%$ was obtained at 60 minutes contact time, while at a contact time of 30 minutes, the removal rate was $48.2 \%$. Clearly during the last 30 minutes, no adsorption occurred, and following that, no tangible difference in removal percentage was noticed; in other words, adsorption had reached equilibrium. Therefore, the optimum contact time was considered 30 minutes. The diagram indicates the effect of contact time on the quantity of diazinon adsorbed onto the activated carbon.

\section{Effects of the adsorbent dose}

The effects of adsorbent dose on removal percentage are shown in Figure 2. The diagram suggests that percentage removal improved with increases in adsorbent dose. Increases were remarkable up to the dose of $10 \mathrm{~g} / \mathrm{L}$, beyond which no conspicuous increases in removal percentage were noticed (i.e. the extra percentage increases in removal efficiency were not cost-effective). Therefore, the optimum dose in this study was considered $10 \mathrm{~g} / \mathrm{L}$. Figure 2 shows the effects of adsorbent dose on adsorption capacity. Results indicated that adsorption capacity declines with increases in adsorbent dose because of the rise in removal percentage.

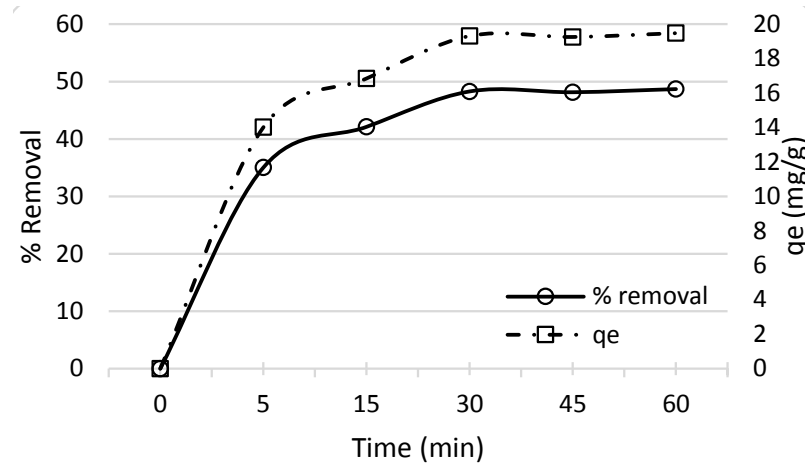

Figure 1. The effects of contact time on adsorption capacity of the adsorbent and on diazinon removal percentage (dose $=0.5 \mathrm{~g} / \mathrm{L} ; \mathrm{pH}=$ $7 ; \mathrm{C}_{0}=20 \mathrm{mg} / \mathrm{L}$ )

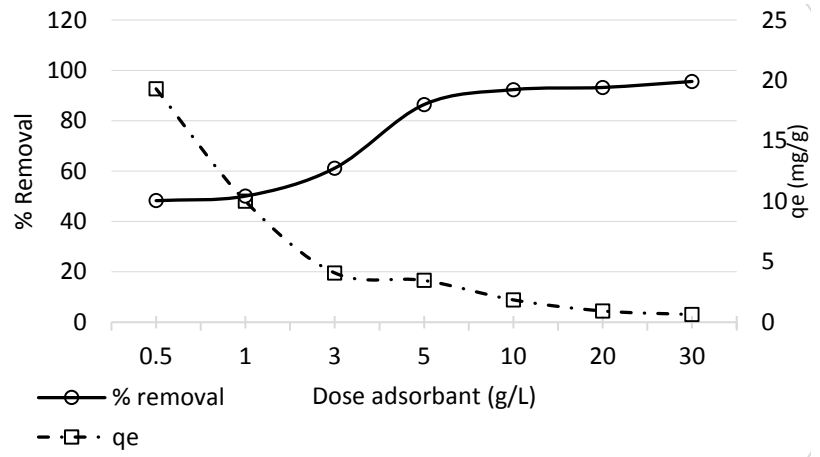

Figure 2. Effects of adsorbent dose on adsorption capacity of the adsorbent and on diazinon removal percentage (time $=30$ minutes; $\mathrm{C}_{0}=20 \mathrm{mg} / \mathrm{L} ; \mathrm{pH}=7$ ).
Effects of $\mathrm{pH}$

Figure 3 shows the effects of $\mathrm{pH}$ on removal percentage. The results indicated that percentages of removal were suitable at all $\mathrm{pH}$ values except for neutral $\mathrm{pH}(\mathrm{pH}=7)$. Furthermore, the effects of $\mathrm{pH}$ on adsorption capacity were satisfactory at all $\mathrm{pH}$ values except for neutral $\mathrm{pH}$.

\section{Effects of initial concentration of diazinon}

The effects of initial concentration on removal percentage are shown in Figure 4. As shown in the diagram, removal percentage decreased and adsorption capacity improved with increases in initial diazinon concentration. At the initial concentration of $5 \mathrm{mg} / \mathrm{L}$, adsorbent dose of $10 \mathrm{~g} / \mathrm{L}$, and $\mathrm{pH}$ of 5 , adsorption efficiency was $100 \%$. The minimum adsorption capacity (about $84.47 \%$ ) was observed at the initial diazinon concentration of $50 \mathrm{mg} / \mathrm{L}$, which was acceptable considering the high initial concentration and the most critical removal efficiency.

Adsorption isotherm models

Langmuir and Freundlich isotherm models were used to study adsorption isotherm models. The linear form of Langmuir (Eq. 1) and Freundlich (Eq. 2) models are as follows:

$$
\begin{aligned}
& \frac{1}{q_{e}}=\frac{1}{a \cdot b}\left(\frac{1}{C_{e}}\right)+\frac{1}{b} \\
& \log q_{e}=\log k_{f}+1 / n \log C_{e}
\end{aligned}
$$

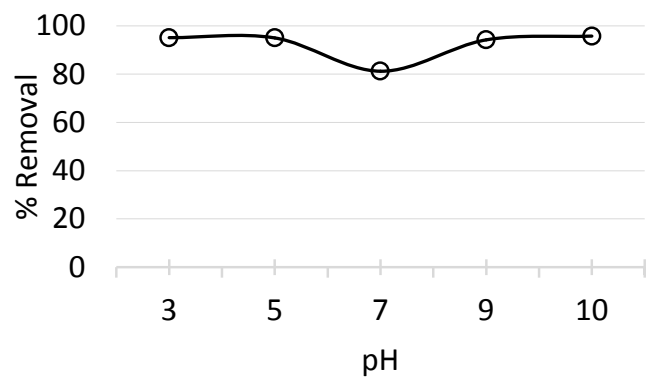

Figure 3. Effects of $\mathrm{pH}$ on diazinon removal percentage (dose $=10$ $\mathrm{g} / \mathrm{L} ;$ time $=30 \mathrm{~min} ; \mathrm{C}_{0}=20 \mathrm{mg} / \mathrm{L}$ ).

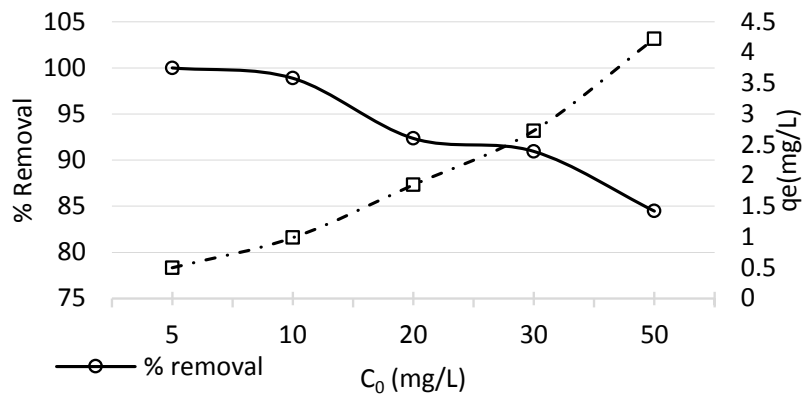

- - $\cdot$ - qe

Figure 4. Effects of initial diazinon concentration on adsorption capacity of the adsorbent and on diazinon removal percentage (time $=$ $30 \mathrm{~min}$; dose $=10 \mathrm{~g} / \mathrm{L} ; \mathrm{pH}=5$ ) 
where $q_{e}$ is adsorption capacity at equilibrium $(\mathrm{mg} / \mathrm{g})$, $C_{e}$ is equilibrium concentration of adsorbate $(\mathrm{mg} / \mathrm{L}), b$ is the maximum monolayer capacity ( $\mathrm{mg} / \mathrm{g}$ ), a is constant absorption related to absorption energy (at a given temperature), and $k_{f}$ and $\mathrm{n}$ are constants of Freundlich related to the capacity and absorption rate, respectively. The isotherm plots are shown in Figure 5. Furthermore, the coefficients of Langmuir and Freundlich adsorption models are presented in Table 2 .

Kinetic studies of adsorption

Data obtained concerning adsorption was studied using pseudo-first order and pseudo-second order models to determine reaction kinetics.

Correlation coefficients for the pseudo-first order and pseudo-second order models were $\mathrm{R}^{2}=0.3461$ and $\mathrm{R}^{2}=$ 0.997, respectively. Results of the present research conform to those of the pseudo-second order model shown in Figure 6. Based on Table 3, the values of the calculated qe $\left(\mathrm{qe}_{\text {cal }}\right)$ and empirical qe $\left(\mathrm{qe}_{\text {epx }}\right)$ are very close to each other, which indicates it is more fitted to the pseudo-second order model. This model was selected as the model for describing the kinetic behavior of the activated carbon produced in Iran for removal of diazinon from aqueous solutions.

\section{Discussion}

Equilibrium time and effects of adsorbent dose, $\mathrm{pH}$, and initial concentration and Langmuir and Freundlich isotherm models were studied in this research. Results of BET experiments showed that the activated carbon produced in Iran was suitable because of its large specific surface area. As shown in Figure 1, removal efficiency improved with increases in contact time to 30 minutes, because increased contact time provided greater opportunities for the adsorbent to come into contact with diazinon ions and adsorb them. Adsorption was rapid at first, but then gradual, possibly due to the presence of active unoccupied sites at the early stages of adsorption, the number of which declined with the passage of time; it may also be due to the reduced possibility of adsorption caused by the repulsive force between diazinon and activated carbon $(1,30,31)$. Statistical studies on adsorbent dose showed that there was a significant relationship between adsorbent concentration and removal efficiency $(P=0.038)$; the extent of adsorption improved, removal efficiency increased, and adsorption capacity decreased with increasing adsorbent mass. As with increases in the adsorbent's mass, a larger surface area of the adsorbent became available, and the number of active adsorption sites increased; therefore, a greater number of diazinon molecules were transferred from the solution to the surface of the adsorbent, thus increasing removal efficiency $(1,28)$. Removal efficiency increased when higher doses of the adsorbent were used, but this increase resulted in reduced adsorption capacity. This phenomenon can be attributed to the utilization of the available surface in the unsaturated state, which leads to the undesirable use of available spaces. This point is economically important in designing large-scale facilities $(32,33)$. As shown in Figure 2, the adsorbent dose of 10 $\mathrm{g} / \mathrm{L}$ was more cost effective and resulted in satisfactory removal efficiency.

Although the optimum $\mathrm{pH}$ was 5 , results of $\mathrm{pH}$ tests indicated a high removal efficiency at all $\mathrm{pH}$ values except for neutral $\mathrm{pH}$; this finding is supported by the results of Moussavi et al, Gupta et al, and Salman et al $(1,28,29)$. Since the pka of diazinon is $2.6(1)$, then it is negatively charged at $\mathrm{pH}>2.6$. On the other hand, the $\mathrm{pHzpc}$ of the activated carbon was 7 . Therefore, in $\mathrm{pH}$ values between 3-7, there was an electrostatic attraction between the pesticide species and the surface of the sorbent. At a $\mathrm{pH}$ of 7 , there was no charge on the surface of the sorbent and (a)

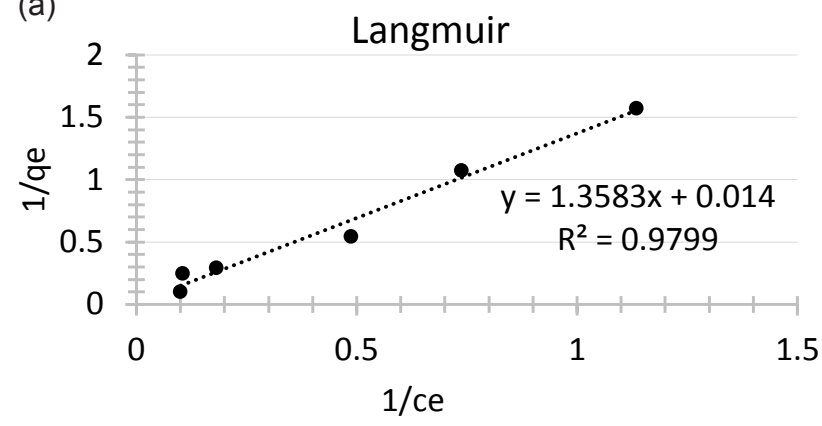

(b)

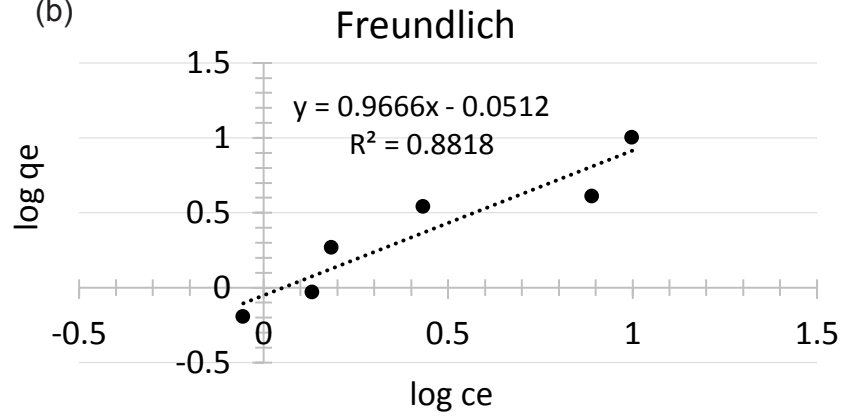

Figure 5. Adsorption isotherm diagrams: Langmuir and Freundlich models.

Table 2. Parameters of the Langmuir and Freundlich adsorption models

\begin{tabular}{llllll}
\hline \multirow{2}{*}{ Langmuir model } & Linear equation & $\mathrm{b}(\mathrm{mg} / \mathrm{g})$ & $\mathrm{a}(\mathrm{L} / \mathrm{mg})$ & $\mathrm{R}_{\mathrm{L}}$ & $\mathrm{R}^{2}$ \\
\cline { 2 - 6 } & $1 / \mathrm{qe}=1.3583(1 / \mathrm{ce})+0.014$ & 71.42 & 0.0103 & 0.0007 & 0.9799 \\
\hline \multirow{2}{*}{ Freundlich model } & Linear equation & & $\mathrm{N}$ & $\mathrm{K}(\mathrm{L} / \mathrm{mg})$ & $\mathrm{R}^{2}$ \\
\cline { 2 - 6 } & $\mathrm{Log}(\mathrm{qe})=0.9666 \mathrm{Log}(\mathrm{ce})-0.0512$ & & 1.034 & 0.888 & 0.8818 \\
\hline
\end{tabular}


Table 3. Constants of the pseudo-first and pseudo-second order models for diazinon adsorption on activated carbon

\begin{tabular}{lccccc}
\hline Kinetic models & $\mathbf{R}^{2}$ & $\mathbf{K}_{\mathbf{1}}$ & $\mathbf{K}_{\mathbf{2}}$ & $\mathbf{q e} \mathbf{e x p}$ & $\mathbf{q e}$ \\
\hline cal & \\
Pseudo-first order & 0.3461 & 0.0291 & - & 19.30861 & 5.01734 \\
\hline
\end{tabular}

(a)

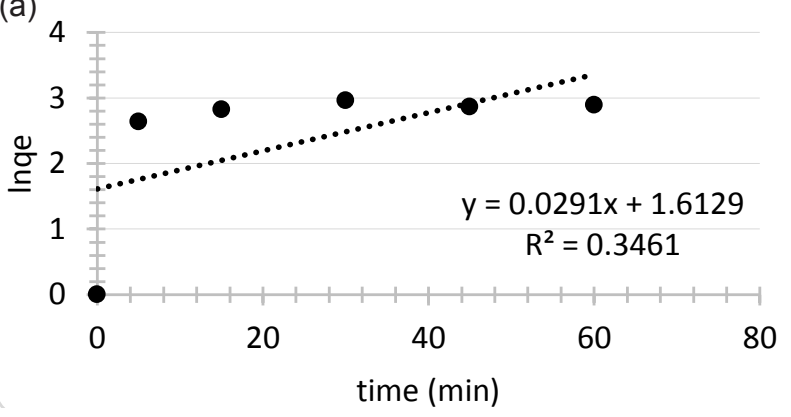

(b)

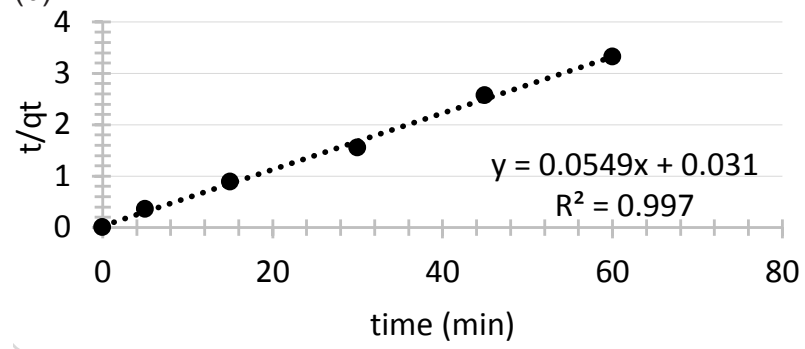

Figure 6. Diagram of adsorption kinetics: (a) pseudo-first order model; (b) pseudo-second order model.

adsorption was reduced. At higher $\mathrm{pHs}$, the adsorption of diazinon was increased. Under basic conditions, other adsorption mechanisms such as hydrogen bonding may be at play instead of electrostatic attraction.

As shown in Figure 4, removal efficiency decreased with increases in initial diazinon concentration, because there were active adsorption sites at low concentrations of the pollutant. However, the number of these active sites declined and the sites were saturated with increases in the concentration of the pollutant, and desorption could take place, which led to reduced removal efficiency. Statistical studies also confirmed this. Pearson correlation coefficient was $(r=-0.83)$, while it must be between -1 and 1 to suggest correlation. The negative sign indicated an inverse correlation. Moreover, the $P=0.003$ indicates there was a significant relationship between the initial concentration and removal efficiency. Maximum removal efficiency was obtained with an initial concentration of $5 \mathrm{mg} / \mathrm{L}$. Adsorption capacity also improved with increases in initial concentration, probably because of increases in the number of molecules that competed with each other to be transferred to the active adsorption sites (34). Results of the present research are in agreement with those of other studies $(26,29,35)$

Using the correlation coefficient $\mathrm{R}^{2}$ as the basis for selection of the obtained data, the present research was more in agreement with Langmuir isotherm, and $\mathrm{R}_{\mathrm{L}}=0.007$ represented a desirable rate of adsorption (Table 2). Ac- cording to the Langmuir isotherm, the maximum adsorption capacity of Iranian activated carbon was $71.42 \mathrm{mg} / \mathrm{g}$. Langmuir model shows whether the adsorbent has one layer and expresses the uniformity of the adsorbent's surface. Fitness to Langmuir model suggests that the active adsorption sites were identically distributed on the surface of the activated carbon produced in Iran. In the study of Ioannidou et al, similar results were obtained that agreed with those of the present study (31). Moussavi et al reported a maximum adsorption capacity of $250 \mathrm{mg} / \mathrm{g}$ for diazinon adsorption onto a $\mathrm{NH} 4 \mathrm{Cl}$-assisted activated carbon (NAC) prepared from a waste biomass. It is noteworthy that no modification was done on the activated carbon used in the present study (1).

Results of the present study indicated the kinetics of diazinon adsorption on activated carbon produced in Iran was better described by the pseudo-second order model. Results of the present study conform to those found by Moussavi et al and Ayranci and Hoda $(1,36)$.

\section{Conclusion}

This research attempted to study critical conditions. Therefore, a high concentration of the pollutant $(20 \mathrm{mg} / \mathrm{L})$ was used as the optimum concentration so that the efficiency of the activated carbon produced in Iran could be evaluated under critical conditions. Results showed that the efficiency of diazinon removal from aqueous solutions attained by the activated carbon produced in Iran was $92.53 \%$ under optimum conditions. Considering the large specific surface area of this activated carbon, it can be introduced as a very good adsorbent. The optimum conditions were a contact time of 30 minutes, initial diazinon concentration of $20 \mathrm{~g} / \mathrm{L}$, activated carbon dose of 10 $\mathrm{g} / \mathrm{L}$, and $\mathrm{pH}$ of 5 . Results of the present study showed that the kinetic behavior of the adsorbent in a contact time of 30 minutes conformed to the pseudo-second order model. Moreover, study of the isotherm models indicated they conformed well to Langmuir model; i.e. the active adsorption sites were homogeneously distributed on the surface of the adsorbent.

\section{Acknowledgements}

The authors of this article would like to express their gratitude to the honorable Research and Technology Deputy of Hormozgan University of Medical Sciences for their financial support of this project.

\section{Ethical issues}

There were no ethical issues in the writing of this article.

\section{Competing interests}

The authors affirm that this article is their original work and have no conflicts of interest to declare.

\section{Authors' contributions}

All authors were involved in all stages of the article. On behalf of the co-authors, the corresponding author bears full responsibility for this submission. 


\section{References}

1. Moussavi G, Hosseini H, Alahabadi A. The investigation of diazinon pesticide removal from contaminated water by adsorption onto $\mathrm{NH} 4 \mathrm{Cl}$-induced activated carbon. Chem Eng J 2013; 214: 172-9. doi: 10.1016/j.cej.2012.10.034.

2. Vymazal J, Březinová T. The use of constructed wetlands for removal of pesticides from agricultural runoff and drainage: a review. Environ Int 2015; 75: 11-20. doi: 10.1016/j.envint.2014.10.026.

3. El Bakouri H, Morillo J, Usero J, Ouassini A. Potential use of organic waste substances as an ecological technique to reduce pesticide ground water contamination. J Hydrol 2008; 353(3): 335-42. doi: 10.1016/j.jhydrol.2008.02.019.

4. Wang Q, Lemley AT. Oxidation of diazinon by anodic Fenton treatment. Water Res 2002; 36(13): 3237-44. doi: 10.1016/S0043-1354(02)00041-6

5. Khoadadi M. Determination of residual concentrations of phosphorus and carbamate pesticides and organiphosphate pesticides in drinking water sources in Hamedan. 12th National Conference of Environmental Health Iran; Nov 3-5, 2009. Tehran: Shahid Beheshti University of Medical Sciences and Health Services; 2009.

6. Ohno K, Minami T, Matsui Y, Magara Y. Effects of chlorine on organophosphorus pesticides adsorbed on activated carbon: desorption and oxon formation. Water Res 2008; 42(6-7): 1753-9. doi: 10.1016/j.watres.2007.10.040.

7. Jafari S. Investigation of pesticides effect on groundwater quality of shemiran villages [dissertation]. Tehran: Islamic Azad University, Science and Research; 2010. [In Persian].

8. Zhou Q, Sun X, Gao R, Hu J. Mechanism and kinetic properties for $\mathrm{OH}$-initiated atmospheric degradation of the organophosphorus pesticide diazinon. Atmos Environ 2011; 45(18): 3141-8. doi: 10.1016/j.atmosenv.2011.02.064.

9. Čolović M, Krstić D, Petrović S, Leskovac A, Joksić G, Savić J, et al. Toxic effects of diazinon and its photodegradation products. Toxicol Lett 2010; 193(1): 9-18. doi: 10.1016/j. toxlet.2009.11.022.

10. Mostafalou S, Abdollahi M. Current concerns on genotoxicity of pesticides. Int J Pharmacol 2012; 8(6): 4734. doi: 10.3923/ijp.2012.473.474.

11. Pirsaheb M, Dargahi A, Hazrati S, Fazlzadehdavil M. Removal of diazinon and 2, 4-dichlorophenoxyacetic acid $(2,4-D)$ from aqueous solutions by granular-activated carbon. Desalination and Water Treatment 2014; 52(2224): 4350-5. doi: 10.1080/19443994.2013.801787.

12. Mostafalou S, Abdollahi M. The role of environmental pollution of pesticides in human diabetes: Int J Pharmacol 2012; 8(2): 139-140. doi: 10.3923/ijp.2012.139.140.

13. Wright DA, Welbourn P. Environmental Toxicology. Cambridge: Cambridge University Press 2002.

14. Androutsopoulos VP, Hernandez AF, Liesivuori J, Tsatsakis AM. A mechanistic overview of health associated effects of low levels of organochlorine and organophosphorous pesticides. Toxicology 2013; 307: 89-94. doi: 10.1016/j. tox.2012.09.011.

15. Rezaei Kalantary R, Dadban Shahamat Y, Farzadkia M, Esrafili A, Asgharnia H. Photocatalytic degradation and mineralization of diazinon in aqueous solution using nano-TiO2 (Degussa, P25): kinetic and statistical analysis. Desalination and Water Treatment 2015; 55(2): 555-63. doi: 10.1080/19443994.2014.928795.

16. Li PC, Swanson EJ, Gobas F. Diazinon and its degradation products in agricultural water courses in British Columbia,
Canada. Bull Environ Contam Toxicol 2002: 69(1): 59-65. doi: 10.1007/s00128-002-0010-0.

17. Farzadkia M, Esrafili A, Baghapour MA, Shahamat Dadban Y, Okhovat N. Degradation of metronidazole in aqueous solution by nano-ZnO/UV photocatalytic process. Desalination and Water Treatment 2014; 52(25-27): 494752. doi: 10.1080/19443994.2013.810322.

18. Shemer H, Linden KG. Degradation and by-product formation of diazinon in water during $\mathrm{UV}$ and $\mathrm{UV} / \mathrm{H} 2$ O 2 treatment. J Hazard Mater 2006; 136(3): 553-9. doi: 10.1016/j.jhazmat.2005.12.028.

19. Humbert H, Gallard H, Suty H, Croué JP. Natural organic matter (NOM) and pesticides removal using a combination of ion exchange resin and powdered activated carbon (PAC). Water Res 2008; 42(6-7): 1635-43. doi: 10.1016/j. watres.2007.10.012.

20. Khodadadi M, Samadi MT, Rahmani AR. Comparison between the efficiency of advanced oxidation process and coagulation for removal organophosphorus and carbamat pesticides. Iran J Health Environ 2011; 4(3): 277-88.

21. Navarro S, Fenoll J, Vela N, Ruiz E, Navarro García G. Removal of ten pesticides from leaching water at pilot plant scale by photo-Fenton treatment. Chem Eng J 2011; 167(1): 42-9. doi: 10.1016/j.cej.2010.11.105.

22. Rodriguez-Mozaz S, Ricart $M$, Köck-Schulmeyer $M$, Guasch H, Bonnineau C, Proia L, et al. Pharmaceuticals and pesticides in reclaimed water: efficiency assessment of a microfiltration-reverse osmosis (MF-RO) pilot plant. J Hazard Mater 2015; 282: 165-173. doi: 10.1016/j. jhazmat.2014.09.015.

23. Samadi MT, Khodadadi M, Rahmani AR, Allahresani A, Saghi MH. Comparison of the efficiency of simultaneous application of $\mathrm{UV} / \mathrm{O}_{3}$ for the removal of organophosphorus and carbamat pesticides in aqueous solutions. Water and Wastewater 2010; 21(1): 69-75. [In Persian].

24. Sanches S, Crespo MTB, Pereira VJ. Drinking water treatment of priority pesticides using low pressure UV photolysis and advanced oxidation processes. Water Res 2010; 44(6): 1809-18. doi: 10.1016/j.watres.2009.12.001.

25. Sanches S, Penetra A, Rodrigues A, Ferreira E, Cardoso VV, Benoliel MJ, et al. Nanofiltration of hormones and pesticides in different real drinking water sources. Sep Purif Technol 2012; 94: 44-53. doi: 10.1016/j.seppur.2012.04.003

26. Ameri A, Srafili A, Farzadkia M, Kermani M, Hajizadeh A. Fenton and Fenton performance review processes for the removal of diazinon in aqueous solutions. 16th National Conference on Environmental Health; Oct 1-3, 2013. Tabriz: Tabtiz University of Medical Sciences; 2013.

27. Foo KY, Hameed BH. Detoxification of pesticide waste via activated carbon adsorption process. J Hazard Mater 2010; 175(1-3): 1-11. doi: 10.1016/j.jhazmat.2009.10.014.

28. Gupta V, Gupta B, Rastogi A, Agarwal Sh, Nayak A. Pesticides removal from waste water by activated carbon prepared from waste rubber tire. Water Res 2011; 45(13): 4047-55. doi: 10.1016/j.watres.2011.05.016.

29. Salman JM, Njoku VO, Hameed BH. Adsorption of pesticides from aqueous solution onto banana stalk activated carbon. Chem Eng J 2011; 174(1): 41-8. doi:10.1016/j.cej.2011.08.026.

30. Srivastava B, Jhelum V, Basu DD, Patanjali PK. Adsorbents for pesticide uptake from contaminated water: a review. J Sci Ind Res 2009; 68(10): 839-50.

31. Ioannidou OA, Zabaniotou AA, Stavropoulos GG, 
Islam MA, Albanis TA. Preparation of activated carbons from agricultural residues for pesticide adsorption. Chemosphere 2010; 80(11): 1328-36. doi: 10.1016/j. chemosphere.2010.06.044.

32. Ong ST, Lee CK, Zainal Z. Removal of basic and reactive dyes using ethylenediamine modified rice hull. Bioresour Technol 2007; 98(15): 2792-9. doi: 10.1016/j.biortech. 2006.05.011.

33. Sulak MT, Demirbas E, Kobya M. Removal of Astrazon Yellow 7GL from aqueous solutions by adsorption onto wheat bran. Bioresour Technol 2007; 98(13): 2590-8. doi: 10.1016/j.biortech.2006.09.010.

34. Kumar Meena A, Rajagopal C, Mishra GK. Removal of heavy metal ions from aqueous solutions using chemically (Na2S) treated granular activated carbon as an adsorbent. J Sci Ind Res 2010; 69(6): 449-453.

35. Akbarzadeh S, Kolahi S. Removal of pesticides parathion, diazinon and carbaryl from drinking water samples to help iron nanoparticles. 16th National Conference on Environmental Health; Oct 1-3, 2013.Tabriz: Tabtiz University of Medical Sciences; 2013.

36. Ayranci E, Hoda N. Adsorption kinetics and isotherms of pesticides onto activated carbon-cloth. Chemosphere 2005; 60(11): 1600-7. doi: 10.1016/j.chemosphere.2005.02.040. 